Article

\title{
Identifying Ecosystem Key Factors to Support Sustainable Water Management
}

\author{
Rudy Vannevel * and Peter L.M. Goethals \\ Department of Animal Sciences and Aquatic Ecology, Ghent University, Coupure Links 653, \\ B-9000 Gent, Belgium; Peter.Goethals@UGent.be \\ * Correspondence: Rudy.Vannevel@UGent.be
}

Received: 31 December 2019; Accepted: 4 February 2020; Published: 5 February 2020

\begin{abstract}
There is a growing consensus that sustainable development requires a behavioral change, forced by firm decision-making. However, existing decision-supporting tools are unlikely to provide relevant information, hampered by the complexity of combined socio-economic and natural systems. Protecting the intrinsic value of ecosystems and providing sufficient natural resources for human use at the same time leads up to a wide span of management, ranging from species traits to governance. The aim of this study is to investigate the interactions between the natural and economic systems from the perspective of sustainable development. The way to reduce systems complexity by selecting key factors of ecosystem functioning for policy and management purposes is discussed. To achieve this, the Pentatope Model is used as a holistic framework, an ecosystem nodes network is developed to select key factors, and a combined natural and socio-economic valuation scheme is drawn. These key factors-abiotic resources and conditions, biodiversity, and biomass-are considered fundamental to the ecosystem properties habitat range and carrying capacity. Their characteristics are discussed in relation to sustainable water management. The conclusion is that sustainable development requires environmental decision-making that includes the intrinsic natural value, and should be supported by ecological modelling, additional environmental quality standards, and substance balances.
\end{abstract}

Keywords: pentatope model; natural valuation; ecosystem key factors; environmental quality standards; ecosystem-economy nexus; natural resources; sustainable ecological limits

\section{Introduction}

As natural resources become scarce and ecosystems seem to degrade despite of all improvement measures, continuous resources abstraction is now subject to a broad public debate, fed by an increasing demand for resources, restrictions on their use, and climate change [1]. At present, a large proportion of the world's population is experiencing water stress [2] and in line with this, the purpose of economic development is questioned and new thoughts on societal functioning emerge (see [3]). The overall policy objective nowadays is to relate a green, circular and sustainable economy and economic growth with resilient ecosystems [4-6]. This 'ecologically sustainable economic development' is defined in Our Common Future [7] as "the process of related changes of structure, organization and activity of an economic-ecological system, directed towards minimum welfare, which can be sustained by the resources to which that system has access." Ecological economics is the scientific domain dealing with the availability, use and allocation of natural resources, envisaging sustainable development within a societal equilibrium. This places ecosystem goods and services (ES G\&Ss), as defined by Costanza et al. [8]), central. Both the economy and ecosystems require system analysis, but also a shift of the focus from the economic system to ecosystems, and from the marketed resources to the biophysical basis, in particular system dynamics and scale issues [9-12]. Current practices focus on the combination of minimum levels of environmental protection and optimal and dynamic societal 
functioning. A societal equilibrium aims to define the amount of ecosystem goods (and services) that can be obtained from nature, enabling economic growth, welfare and social well-being, without causing ecosystem damage. Conflicts on this question are shown by Dudgeon [13] and Kingsford [14]. These examples broaden the discussion from physical resource flows to policy and management. They also lead to the basic idea of 'inclusive development', and in particular to ecological inclusiveness, aiming to safeguard biodiversity and ES G\&Ss by reducing resource extraction and pollution, to value ecosystems and natural wealth, to address socio-ecological issues applying multi-level governance strategies, and to ensure access and allocation of resources [3]. This makes sustainability subject to quantification and valuation as illustrated by, amongst others, the European Commission's integrated ecosystem assessment [15].

Valuation of natural capital gains growing attention, given the developments of environmental accounting, ecosystem services, and related valuation methods. These developments respond to an urgent need of action that results from a changing society facing a higher level of governance complexity. Complexity is relative and, as Braat [16] argues, seems enormous to human-environmental systems because of our limited understanding of systems dynamics, and because those systems do not follow the rules planners try to impose on them. Too long, dominant perspectives and environmental management were based on the assumption that a stable and infinitely resilient environment or target resources (such as fish populations and pests) could be controlled, and a stressed nature would self-repair into equilibrium. This contrasts with, for instance, the experience that small changes in vulnerable systems may cause dramatic consequences, or that management of complex systems is full of uncertainty and surprises [17]. This vision coincides with the 'consumer sovereignty' that dominates conventional economic decision-making and threatens the overall system that should be ecological, social and economically sustainable [10]. For example, current practices of economic valuation of water resources depend on the consumer preference and on the perception of changes in well-being through ecosystem impacts [18].

Societal developments include numerous environmental issues, as is shown by the megatrends described by international authorities (see $[6,19,20]$ ). The environmental threats and challenges are elucidated in the European Union document "Living well, within the limits of our planet" [21], aiming to protect the natural capital, to improve policy coherence, and to develop society sustainably. Above all, there is the EU's attempt to ensure "that economic and social progress is achieved within the carrying capacity of the Earth, by increasing understanding of planetary boundaries" [21].

This paper examines the relationship between ecosystems and the economy. This makes the subject, by definition, interdisciplinary, combining environmental sciences and socio-economic aspects with governance. In practice, this leads to the examination of the mutual interactions between ecosystem functioning, the availability of natural resources and decision-making. In addition, the focus is on sustainable use of natural resources. According to de Jonge et al. [22], the context of the issue is that market failure and poor governance fail to allocate ecosystem resources efficiently, that it is unknown how much technology can help to avoid breaching of sustainable levels of ecosystem utilization, that this results from a lack of information on ecosystem functioning and valuing, and that it is unknown how to maintain natural stocks and flows that serve ES G\&Ss. The allocation of ecosystem resources can be considered the fourth step of sustainable use. The first step-introduced by, among others, Costanza et al. (see $[10,11]$ - — defends the idea that humans depend on ES G\&Ss. The second step is the quantification of resource availability and uses, which is the domain of environmental accounting and statistics, and also includes indicators such as the Water Footprint concept [23] and the Water Exploitation Index [24]. The third step is defining sustainable use, which means setting limits to the use of natural resources (ES G\&Ss) on the one hand, and on the environmental impacts on the other hand. This is the subject of this paper. The concept of ES G\&Ss is a common factor in the human and natural capitals concept and allows to explore the monetary and non-monetary values of natural resources, depending on the internalization of goods and impacts. This must challenge to address the intrinsic value of ecosystems - which decision-makers usually consider an economic externality. 
A very important notice on valuation is that abiotic and biotic ES resources are to be valued in different ways. Part of these natural resources are ES G\&Ss to which apply different "languages of valuation" [25], being either monetary or intrinsic, depending on the economic, social or ecological point of view. In search of the key factors that determine the value of ESs and ES G\&Ss, a mind-frame is constructed to define the limits of resources use in terms of sustainability.

One of the recommendations formulated by de Jonge et al. [22] is that "by understanding the role of ecosystem functioning and ecosystem service provision to human well-being it is possible to identify and target the natural assets of a system and so accomplish for sustainable development requirements." There is a wide 'span of control' between the knowledge of fundamental systemic processes, impact analyses, and policy and management, that operate across the societal (social, economic, and natural) capitals and range from a local to a global level. The long track between the ecosystem's functioning and governance reads as follows: (1) functional traits of (groups of) organisms reflect the most fundamental processes and dynamics of ecosystem functioning, and can be reduced to a selected number of key factors, (2) those key factors can be physically expressed in terms of ES value and quantified by means of models and balances, (3) ES values enable to set limits by means of EQSs, (4) EQSs determine the availability of resources, and at the same time the limits of resource use, (5) ES G\&Ss identify the use of resources in terms of sort and volume, that can be valued according to different valuation languages, and (6) governance should regulate all of this within the objective of sustainability.

The main objective of this study is to investigate the 'ecosystem-economy nexus' in the sense of sustainable use of resources. From this, secondary objectives have been formulated: (1) design of a conceptual model: to get the idea of intrinsic natural value incorporated into environmental governance, (2) to support modelling: to propose a means to quantify natural resources, and (3) to clarify environmental sustainability: to define safe limits of sustainable use of natural resources and to illustrate that exceedances means environmental harm on the one hand and unsustainable economic growth on the other hand.

\section{Materials and Methods}

This paper describes a conceptual approach for practical use in water resources management and should serve as a basis for the design of technical tools. However, no guidance is available for developing this kind of conceptual framework that inevitably tends to be more holistic compared to the reductionistic approaches of technical tools used in cases studies. Therefore, the concept of systems thinking [26] was applied within the restraints of the objectives and with the focus on the clarification of the ecological fundaments. This resulted in a more generic approach that was validated against examples within the water domain. The basic idea to elaborate on the 'ecology-economy nexus' gradually evolved towards a deeper exploration of the basic ecological concepts, often obtained from early sources of ecological thinking, combined with recent scientific developments (such as species traits).

This resulted in the following steps:

- Design of a common framework for (natural) resources valuation, including aspects of governance.

- The development of a combined economic/natural values scheme.

- Selection of the key factors of ecosystem functioning.

- Selection of the key factors of natural resource valuation and development of a typology of nature-related values. Types and key factors are combined in a resources valuation scheme.

- Description of the interactions between key factors.

- Defining the limits of natural resources use and proposing criteria to meet the societal equilibrium and support governance. Those criteria result in additional EQSs. 


\section{A Common Framework for Resources Valuation}

It is possible to explain the functioning of the society by means of a small number of interacting frameworks. In [27,28], the Pentatope Model (PTM) is proposed as a holistic framework for societal, and, in particular, environmental analyses. It includes five (sub)frameworks, with each framework composed of five factors (Figure 1):

- Societal Capitals: the social, economic, and natural capital, spatial infrastructure, and their 'functions and uses'.

- Ecosystems: the terrestrial, aquatic, and atmospheric ecosystems, biota, and their ecosystem functions.

- Environmental Information Cycle (EIC): monitoring, data management, reporting, knowledge.

- Governance: law, science, politics, public administration, policy and management (P\&M).

- DPSIR: driving forces, pressures, states, impacts, and responses.

The basic idea is that societal systems are dynamic, and inevitably cause disturbances between capitals. Environmental disturbances are part of a cycle including environmental analysis, information sharing and governance steering. Information sharing deals with data and knowledge generation and exchange, including the status of ES conditions and valuing and valuation (V\&V) of capitals. As it will be made clear further in this document, water valuing is a recognition of the cultural, aesthetic, social and environmental values of water and water services, whereas valuation is economic, attaching a monetary value to the benefits and costs of water services [29]. V\&V should be based on a series of changes of pressures, that impact ecosystem states, require recovery efforts, and justify additional responses. Calculating the efforts for ES recovery is an impact analysis and provides evidence to governance. The conceptual basis for this is provided by GASI, which stands for Governance by means of Actors-Subjects Impact analysis [28]. In this paper, the actors are the social and economic capitals (socio-economic drivers, activities, and pressures), the subject is the natural capital (habitats or ecosystems), and impact analysis deals with physical accounting, at the same time providing the data for governance. Impact analysis requires modelling which is highly developed for separate socio-economic and ecosystem (or biophysical) models. Few examples exist of linked or integrated ecological-economic models, but ecosystem modelling is expanding towards ES G\&Ss for more than a decade. These aspects are shown in the V\&V scheme (Figure 1). This scheme also shows the nexus between governance and societal capitals (P\&M instruments), and between the socio-economic capital and ecosystems (ES G\&Ss).

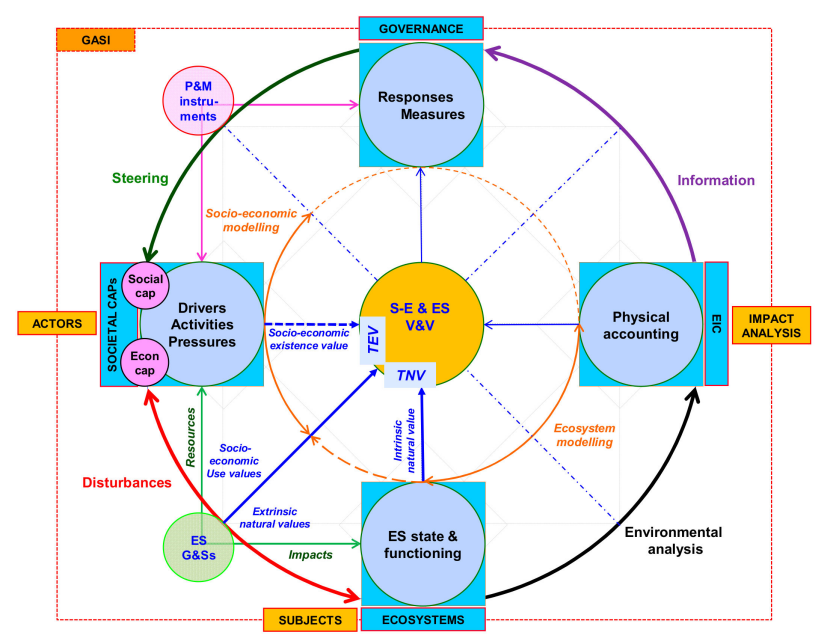

Figure 1. Valuing/valuation $(\mathrm{V} \& \mathrm{~V})$ scheme. This framework combines the Pentatope Model, the GASI concept, and the TEV-TNV values scheme. The impact analysis according to GASI includes the ecosystem (ES) and social and economic (S-E) valuation (monetary) and valuing (non-monetary). 
The United Nations' System of Environmental-Economic Accounting for Water (UN SEEAW) distinguishes between environmental (physical) and economic (monetary) accounts [30]. In Vannevel [28], physical accounts are illustrated by means of water load balances, calculating nutrient load reductions required to meet EQSs. That paper also suggests opportunities to further elaborate on the role of ES G\&Ss, EQSs, valuation of natural resources, and environmental accounts within the PTM concept. ES G\&Ss are of a higher order of complexity compared with chemical substances. They include biotic components, with different ES requirements, which makes it difficult to establish EQSs and to valuate. Keeler et al. [31] and the Millennium Ecosystem Assessment [32] describe frameworks for valuing and valuating water impacts.

These studies deal with disturbances, with the focus on differences in conditions (changes, effects) of the natural system according to socio-economic activities. They also consider relative changes in values (losses or gains) to calculate reduction efforts or to apply valuation techniques. Valuation is based on marginal changes in goods and services provisioning [31]. This offers opportunities for alignment with the Total Economic Value (TEV) Framework of the Millennium Ecosystem Assessment [32]. However, a number of remarks emerge from a critical look at the TEV classification (Figure 2):

- TEV covers socio-economic activities and hence not only economic, but also social values;

- TEV is dependent on ES G\&Ss from which intrinsic natural values are excluded by definition;

- Economic value stands for monetizable and commodifiable goods and services, but intrinsic natural values are not of that kind since they are incommensurable in economic terms;

- Use and non-use values are only meaningful in a socio-economic context and relate to the extent ES G\&Ss support human activities;

- Being part of non-use value, existence value can only apply to intrinsic social (e.g., well-being, ethics, self-esteem, cultural identity) and economic (e.g., company image) values, and there is no common denominator with natural intrinsic values including biodiversity and habitats.

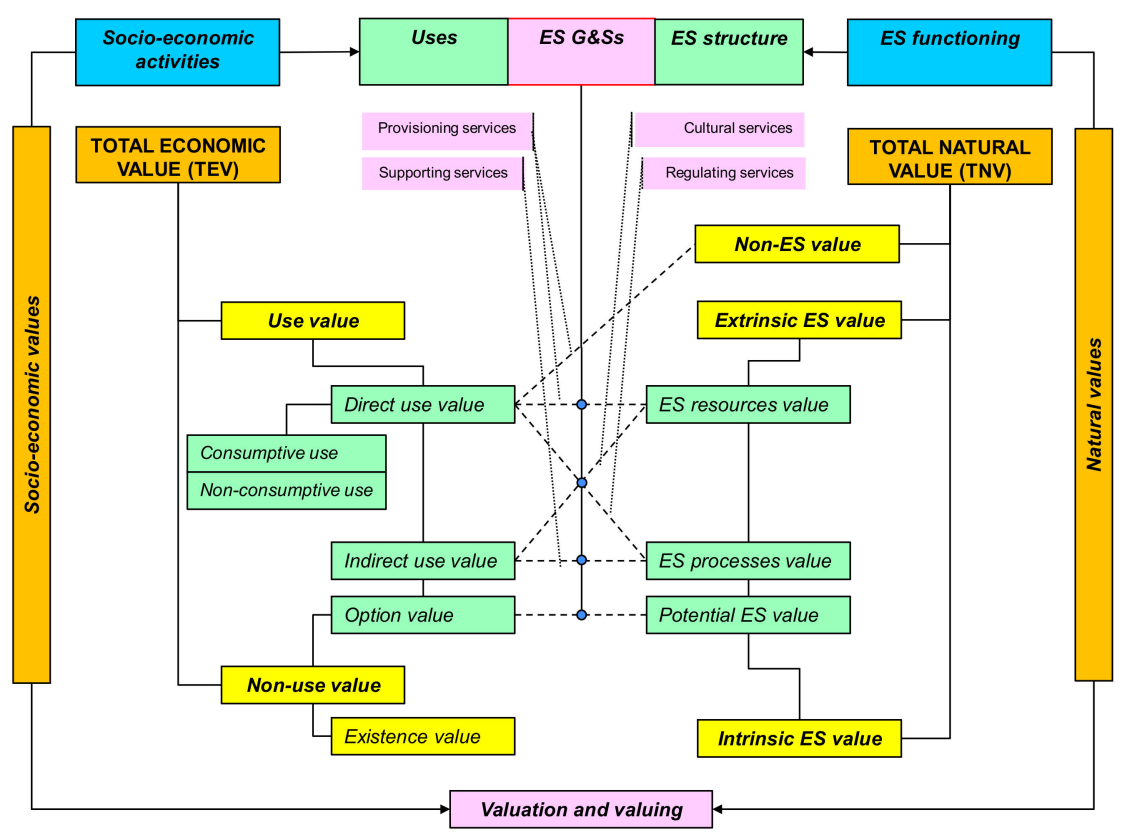

Figure 2. Societal values classification. The Total Economic Value (TEV) is completed with the Total Natural Value (TNV), to which apply both non-monetary valuing and monetary valuation. TEV-TNV interactions combine different types of ES G\&Ss related to use values, as described by the Millennium Ecosystem Assessment [32]. 
As a result, considering TEV socio-economic values only seems more appropriate. Within the concept of this paper, socio-economic values cover direct and indirect market-based (expenditures, costs) values, and intrinsic social and economic values. Opposite to TEV, there is the natural valuation, dependent on ES functioning. ES functioning is the aggregation of processes, structure, and resources (cf. [22]) and the assumption "that the sustainability of ecosystem services is dependent on functioning ecosystems" as formulated by Apitz [33] is supported. On this basis, it is proposed to categorize natural value as:

- Ecological, ecosystem or biogeochemical processes: fundamental dynamics of ES at different levels or organization, including or related to: (i) biogeochemical processes: e.g., self-purification of water, feeding, reproduction, and migration at species level; (ii) ecosystem properties and concepts: e.g., carrying capacity, resilience, ES health, and sustainability. Berkes [34] mentions a number of characteristics of complex systems that rather fit processes: path-dependency, tipping points, and self-organization;

- Structure: factors or elements that connect processes and the way they are organized and composed, such as community structure (trophic structure, species composition), food web structure, and related complexity. Berkes [34] also mentions scale effects, nonlinearities, and connectivity;

- Resources: available physical abiotic and biotic stocks and flows, such as nutrients and organisms. Stocks and flows are the basis of physical accounts in the form of balances.

A similar approach was drawn by de Jonge et al. [22] on which will be further elaborated. In se, 'value' is only meaningful in terms of human appreciation, and 'use' in terms of human activities. Any natural resource or process that is effectively or potentially of human use, or supports it, is called an extrinsic value. Then, the Total Natural Value (TNV) adds extrinsic and intrinsic values. The difficulty is that both values apply to the same physical goods in a different way: biodiversity and habitat quality are intrinsic, but tradable species and landscapes are extrinsic. However, the fact that many people recognize only a few species important makes many other species unappreciated, as well as their habitat and related ecological processes. Disturbances make hidden processes such as pollination and pest control visible, showing that an intrinsic value is also extrinsic to some extent. In addition, mining resources are also natural resources, but are not part of the ecosystems. As a result, natural values can be categorized as follows:

1. Intrinsic natural/ES value: non-commodifiable ES value, expressing the importance of maintaining systemic conditions of resources and processes and including, amongst others, natural capital value (species and habitat diversity), evolutionary processes (speciation), and ES integrity (complexes of related ES elements and processes). Strictly considered, this includes pure intrinsic value of nature; in a broader sense, this covers any non-monetizable natural value (more or less the cultural services, such as heritage landscapes) [22];

2. Extrinsic natural/ES value: commodifiable ES values:

a. Ecosystem resources value: benefits from ESs, transferable as goods and services (ES G\&Ss) and subject to commodification (monetary valuation) by means of economic valuation and social valuing;

b. Ecosystem processes value: benefits from ESs, not explicitly commodified, but they can be valued in socio-economic terms. Examples of socio-economic valuing include avoided costs, such as maintaining superficial groundwater levels that avoids carbon release (and reduces global warming) or damages to buildings (social discomfort);

c. Potential value, including, for instance, the scientific importance of species or habitats;

3. Non-ecosystem value: natural value that is not part of the ES functioning.

Apitz [33] formulated a consideration about ecosystem service provision (and resilience or vulnerability), dependent on spatial relationships such as habitat connectivity, the connection of 
habitats via the hydro-cycle, the concentration and distribution of stressors, and the human use and value of various habitats and services. ES G\&Ss act as a 'supply-and-demand filter of values' in the way they identify the kind and availability of ES resources and processes for human needs, and of which the latter can never exceed the former. The combined economic and natural, or societal, values scheme (Figure 2) shows the purely ecosystem values, of which some or parts are for human use in terms of ES G\&Ss, and the correlations between the socio-economic and natural values classifications. The importance to distinguish between intrinsic and extrinsic natural values is that it allows to value the ecosystems in total, as well as the ES G\&Ss for direct and indirect uses in particular. This is crucial when discussing the allocation of resources to human uses, compared to the availability of natural resources. It is also important to optimize, maximize or improve processes of ES functioning to secure the provisioning of ES resources. In general, socio-economic uses are dependent on the ES structure (design) according to its functioning. The output of ESs is ES resources that are dependent on processes, and processes on abiotic (abiotic conditions) and biotic (functional traits) properties. Both resources and processes should secure intrinsic values. This leapfrogs the suppressed discussion on intrinsic ecosystem values to the governance level, to become part of a broader societal debate. However, it also forces to detail the factors and processes that are characteristic of natural values in relation to human uses.

The study area explored hereafter focuses on the intrinsic and extrinsic natural resources value in relation with the socio-economic values and ES G\&Ss. Not included are other resource values (human, financial), or valuations of other frameworks (Governance, EIC). Recognizing that intrinsic ecological values are highly important, but difficult to quantify in economic terms [31], the focus is not on developing appropriate quantification tools, but on exploring the way to incorporate them in decision-making, hereby facing the global objectives. The pathway from natural resources to governance requires a pavement with stepping stones on the identification of key factors of ecosystems, ES G\&Ss, and EQSs.

Scientists point on the importance of developing structural models to analyze human interactions within complex socio-economic systems, but also recommend to reduce the number of model nodes and interactions to keep it simple and realistic at the same time [22]. Elaborating further on the valuation of ecosystems and ES G\&Ss therefore requires to identify the key ecosystem factors in this context.

\section{Key Factors of Ecosystem Functioning}

Discussing ecosystems starts with the fundamental distinction between the non-living (abiotic) and the living (biotic) environment (Figure 3). The abiotic environment covers the living conditions created by the environment, as well as the availability of resources for housing and feeding. An organism cannot occur beyond the constraints of the abiotic environment [35], which recalls to Liebig's Law of the Minimum and Shelford's Law of Tolerance. The dependencies of species on these conditions and resources are known as species traits, for the reason the figure distinguishes between abiotic conditions and resources traits. Species traits are specified functional attributes of an individual species that reflect its adaptation to its environment, of which some can affect ecosystem functioning (functional traits) or can be used as measures of community functional diversity [35,36]. Examples of species traits that apply to aquatic invertebrates include drift propensity, trophic level (feeding habit), respiration, substrate and sediment preference, thermal and pollution tolerance, and life cycle (e.g., r-/K-strategists) [35-37]. Feeding creates biomass, which is the weight of an individual, a population, a community, or a higher ecological unit. As such, the biomass produced by one species provides biotic conditions and serves as a biotic resource for other species, of which the populations increase by reproduction, and of which, in turn, individuals make use of available abiotic and biotic resources. In this way, biomass is distributed over species within a community. It indicates the extent of a population, which is an important biodiversity indicator since the decrease of a population is a far more sensitive indicator than species richness [38]. The process of biomass distribution depends on the species' features, of which combined sets are known as functional traits. Functional traits are morphological, behavioral 
and reproductive properties of a species that explain its ecological functioning [39], e.g., feeding mechanisms and abiotic conditions and resource requirements. Feeding is considered an essential factor in structuring invertebrate communities and there is a strong link between feeding strategy and ecosystem functions [37].

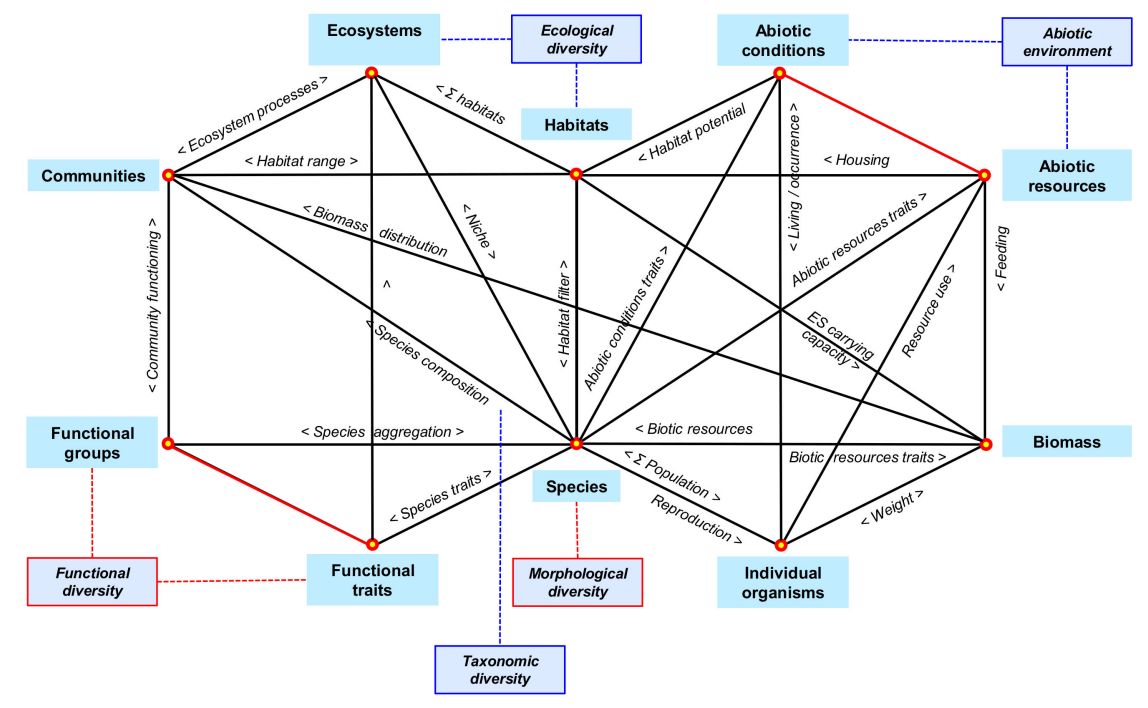

Figure 3. The ecosystem nodes network. The network shows nodes of the abiotic and biotic environment and their interactions. Ecological, functional, morphological and taxonomic diversity are different types of biodiversity that relate to one or more nodes or interactions between nodes.

Instead of the ecosystem level, it is preferred to follow Sir Arthur George Tansley (1871-1955) who regarded habitat as the fundamental unit of ecological organization and "envisioned the biological and physical parts of nature together, unified by the dependence of animals and plants on their physical surroundings and by their contributions to the maintenance of the physical world" [40]. Abiotic resources are essentially a part of the abiotic conditions. These conditions define the boundaries for living on a location, indicated as 'habitat potential'. In this respect, Segadelli et al. [41] investigated the effects of extreme precipitation on biodiversity in mountainous regions. The created (realized) habitat is a result of the habitat potential and the occurrence of species that occupy the territory. This means that the habitat filter concept applies, sorting out species that do not possess appropriate functional attributes (species traits) matching the environmental conditions $[35,36]$. In fact, both abiotic and biotic filters apply at different temporal and spatial scales [36], with the result that similar potential habitats will have a different development and species composition. Habitats help to describe a community in terms of occupied ranges of habitat conditions ('habitat range') based on its species composition. A typical typology of aquatic communities distinguishes between plankton, nekton, neuston and benthos. An ecosystem is a higher aggregation level of habitats.

The functioning of a community can be explained by functional groups. Functional groups are aggregates of species within a community, according to organismal attributes that are subject to natural selection, and sharing equal characteristics, performing equal tasks, producing resembling effects to external factors, and hence, sharing an ecological niche [35]. Examples of functional groups are: predators, herbivores, decomposers, pollinators, and nutrient transporters [17]. These groups represent a biomass. The biomass production within a habitat is indicated by 'ecological or ecosystem carrying capacity' (ES CC).

'Species' is a basic component in the biodiversity concept, as it is an aggregation of individuals (population) on the one hand, and part of a higher level of aggregation (communities) in terms of species richness on the other hand. Biodiversity is by far the most important factor for ecologists and politicians, associated with "a measure of the variety of organisms within a local area or region" [40]. 
At present, the definition by the United Nations Convention on Biological Diversity is commonly applied: "the variability among living organisms from all sources including, inter alia, terrestrial, marine and other aquatic ecosystems and the ecological complexes of which they are part: this includes diversity within species, between species and of ecosystem" [42]. However, different forms of biological variation are being distinguished: taxonomic (usually species diversity), ecological (often ecosystem diversity), morphological (genetic and molecular diversity), and functional (relating to the species' role and functioning) diversity (see, inter alia, [43-45]). In this approach, functional traits and functional groups are considered part of functional biodiversity. Apitz [33] defends that functional diversity is more important than species diversity in sustaining ecosystem services, and that favouring specific ES G\&S on one site (or system) will affect other services on that site or connected sites. Figure 3 indicates these types of biodiversity.

Key nodes can be selected from this network schema for discussing natural valuation. Meaningful selection criteria are those that support or include quantity or quality aspects for intrinsic and monetary ecosystem valuing and valuation. Since the main objective is to maintain sustainable ecosystems, the focus is on safeguarding ecosystem processes, and habitat, and species protection in relation to human activities.

Abiotic conditions and abiotic resources, and biomass and biodiversity are considered key factors, along with determining properties of ecosystem processes including ecosystem carrying capacity and habitat range (Figure 4). Ecosystem carrying capacity is the potential to create biomass with the available resources; habitat range allows species to occur within an area with limited environmental conditions. The habitat level allows to combine species composition and their functional role in relation to ecosystem functioning and human activities [22]. A striking example is provided by Graham et al. [46]. Called 'ecosystem properties' (cf. [22]), Costanza et al. [10] mentions ecosystem carrying capacity and resilience as determining elements of ecological sustainability. Ecosystem resilience will be considered in a further stage in this paper. There is a natural balance-indicated as ecosystem (or natural) equilibrium-between the ecosystem carrying capacity and the habitat range. Combined, carrying capacity and habitat range define the ecosystem value, both biotic and abiotic, or extrinsic and intrinsic.

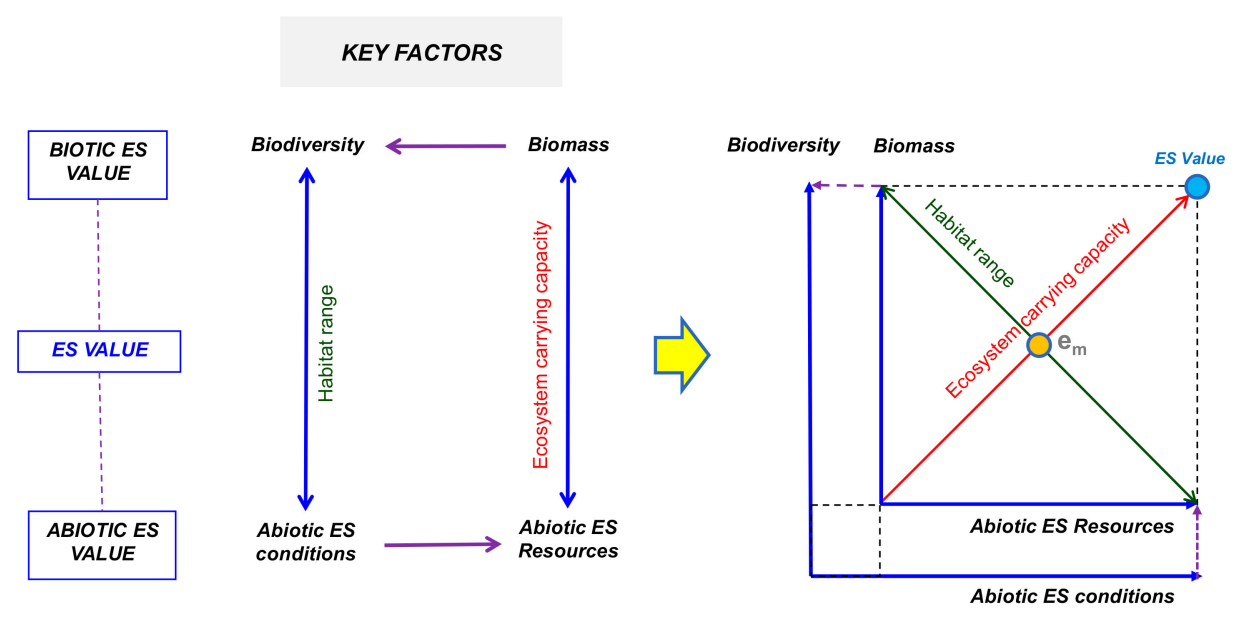

Figure 4. Ecosystem key factors. Selected key factors of ecosystem functioning are rearranged in a diagram including habitat range and ES carrying capacity. ES value is the total abiotic and biotic value. The minimum ES equilibrium $\left(\mathrm{e}_{\mathrm{m}}\right)$ is the minimum carrying capacity to be generated within the limits of the habitat to maintain biodiversity.

The selected key ES factors allow the design of a natural values scheme as a basic component of a societal values scheme. 


\section{A Societal Values Scheme}

The description of a societal values scheme is based on the above mentioned societal values classification on the one hand, and the ecosystem nodes network (resulting in the ES key factors) on the other hand. As the socio-economic part includes human activities, additional key factors and values emerge.

The challenge of sustainable development is to develop natural resources balances of an ecosystem or economy according to a societal (ecological-economic-social) equilibrium, ensuring the long-term functioning of the societal capitals. To achieve this, the process of interactions between the environmental and economic capitals must be drawn first, linking the ecosystem (or ecological) and economic carrying capacity and equilibrium, and the role of ecosystem goods and services. A balance is a quantified flow-chart. Theoretically, any element of an environmental process should be quantifiable, but this seems almost impossible in practice. Ecosystem (ES) valuation mostly focuses on putting a value on ecosystem goods and services for developing policy tools (see indicators as defined in [15]). However, the ultimate goal is to meet and balance both the ecological and economic equilibrium, which requires the valuation and valuing of societal capitals. For simplicity, only the term 'valuation' will be used further in this study, unless distinction is necessary. The terms 'natural value' and 'ecosystem value' are introduced and used as an undetermined unit, since there is no common denominator (metric) —called incommensurability (cf. $[47,48]$ )—including the economic, ecological and social values.

In the societal values schema (Figure 5), the notion 'natural value' is the cornerstone of understanding the linkage between environmental and economic valuation. The natural value includes both ES value and non-ES value, determined by biogeochemical processes. Non-ES value (such as fossil fuels or rare earths, radio-active substances and some minerals) is part of the (non-human) environment, but is normally not contributing to ES functioning. However, because these resources are substances withdrawn from the natural environment, they are commonly referred to in literature as ES goods, indicated in the schema as 'natural non-ecosystem goods and services'. Any other environmental resource, either of abiotic or biotic nature, is considered having 'real' ES value. Abiotic ES value includes a number of non-living resource types (water, minerals) that support ecosystems and occur in nature in different quantities. Biotic ES value covers all organisms (living forms) and is the degree the created biomass is distributed over a number of species (species richness, biodiversity) —or-the total of the population biomass of all species. Biodiversity is considered essential to the self-organization of complex adaptive systems, both in absorbing disturbances and in re-organizing the ecosystem after a disturbance [17]. The degree the abiotic environment is capable to produce biotic value is known as ecosystem carrying capacity. Combined, the abiotic environment (abioticum) and biotic environment (bioticum) determine the habitat conditions. Part of their quantities-considered abiotic and biotic ES G\&Ss-are exploitable to serve human needs. It is a scientific and managerial challenge to mark their exploitation (abstraction, harvesting) limits. The amount and kind of abiotic and biotic resources available or produced determine their use. It is therefore important to monitor ES G\&Ss and to detect trends in their potential provision or in changing demands for those ES G\&Ss [49]. Some species serve as biotic ES G\&Ss as they are harvested or cultivated in intensified ways by means of agriculture, fishery, or animal husbandry. Yields depend on biological factors, in particular the population dynamics of the species considered, as well as on economic factors, such as demand and supply. Yields and abstractions of abiotic value determine the socio-economic production and consumption process, ultimately ruled by human demand and supply. The extent resources are available to produce commodities (products) indicates the economic carrying capacity, its economic value being determined by the commodities' quantity and quality. Opposite to the monetarized economic value stands the ecosystems' intrinsic value, which is a human valuing of ecosystems in terms of habitat quality and biodiversity. From this, it must be concluded that ES G\&Ss also include 'non-ecosystem' goods and that the economic process is largely resource-, and hence, quantity-driven. It can be noticed that ecosystem and non-ecosystem goods support the material economy, whereas ecosystem services, such as recreation or the capacity of 
natural breakdown of pollutants in the water system, do not, or much less, or only indirectly influence economic pricing.

Any resource use will affect the ecological equilibrium and hence, impacts the abiotic and biotic value to a lesser or greater extent. This is denoted by return flows, showing the circular flow of substances and materials from (resources) and back (waste) to the ecosystem. Sustainable development aims at limiting the amount of ES G\&Ss use to the degree they meet both the economic and ecological equilibrium. From this, we must conclude that, in general, goods are largely determining the process, whereas services and in particular those reflecting 'intrinsic values' of habitats or biodiversity, are not directly related to the socio-economic capital and its pricing.

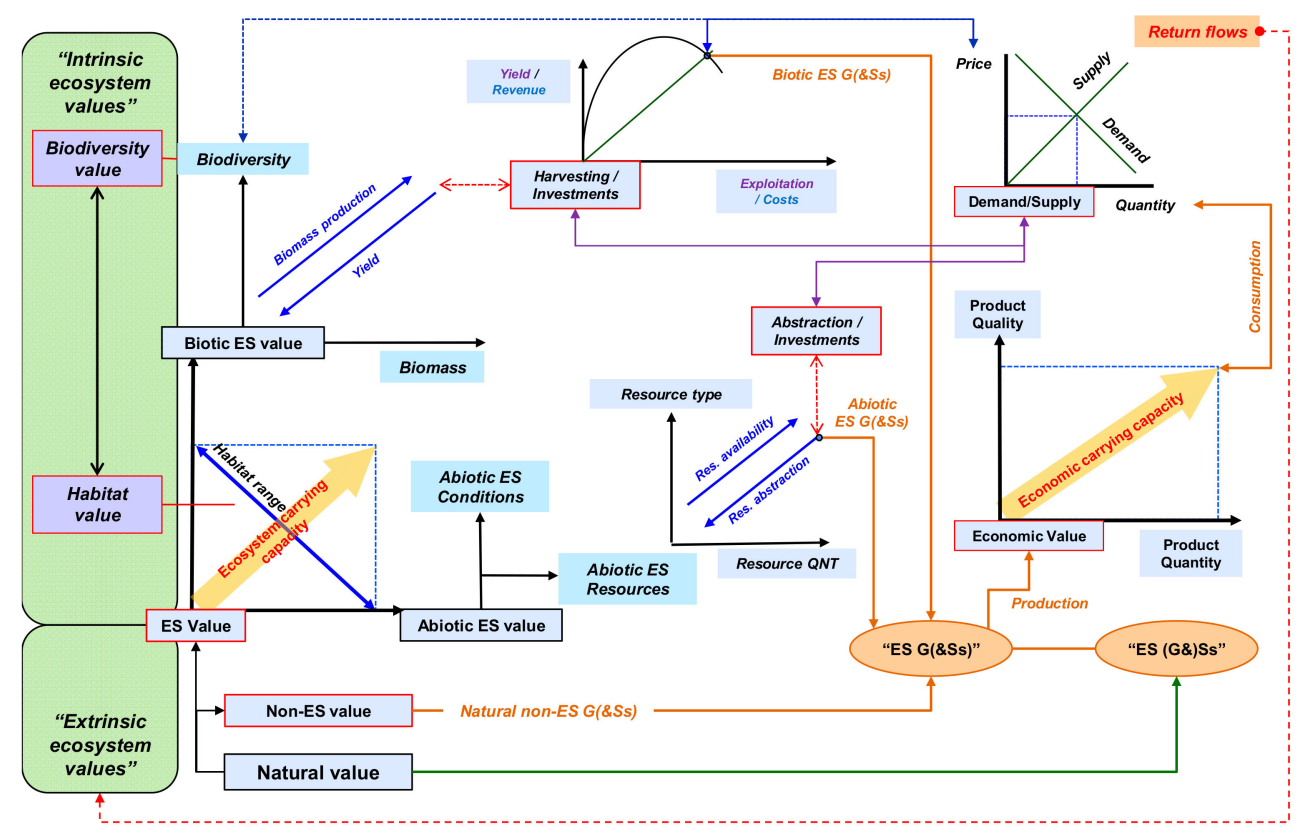

Figure 5. Societal values scheme. Related natural and socio-economic values and flows of environmental goods and services are depicted. Demand and supply of products determine the amount of physical goods to be abstracted from the natural ecosystem and non-ecosystem environment. Pricing is the economic quality factor, but it does not reflect the ecosystem's intrinsic quality, such as biodiversity (dotted line).

A continuous and increasing economic pressure (by harvesting or abstracting resources) on ecosystems contributes to population decreases and species extinction. Whereas ES resources and commodities (product quantity) are physically depending on each other, biotic value and economic pricing are not. Moreover, economic important species and habitats becoming rare are considered a loss of natural value, but gain economic value when they become a scarce good.

\section{Interactions between Key Factors}

Figure 6 shows different cases of human intervention that result in changing environmental conditions:

- conceptual situation (a): the abiotic status (state of the environment, SoE) is in line with the biotic status, with ES value optimally reflecting the ES CC within the HR;

- managed ESs with intensified cultivations (agriculture, aquaculture) (b): the habitat range is very low as both the number of species and the living conditions are reduced, in favour of ES CC increase to maximize biomass production. Low species richness and high biomass result in large populations of the selected species; 
- nature management (c): the objective is to maintain or increase biodiversity, which implies maximization of the HR by improving habitat conditions; this is often accompanied by reducing resources (and hence, EC CC) to favour sensitive species;

- urban area (combining different human disturbances) $(\mathrm{d})$ :

- physical impacts: cause loss of habitats and results in species reduction and hence, a lower HR;

- toxic chemical impacts: results in a lower habitat range because of species reduction — eventually with associated unused habitat potential—and hence, a lower EC CC;

- nutrient enrichment: increases ES CC with a smaller number of species, with reduction of occupied HR following the loss of sensitive species.

The different forms of ES management can be illustrated by a few examples. Vitousek et al. [50] compares three agricultural production systems worldwide to conclude that large differences exist between nutrient balances, with excesses resulting in eutrophication, or inadequate inputs causing low productivity and land degradation. Martín-López et al. [51] illustrates the dependence of grazing and the carrying capacity for the Doñana National Park.
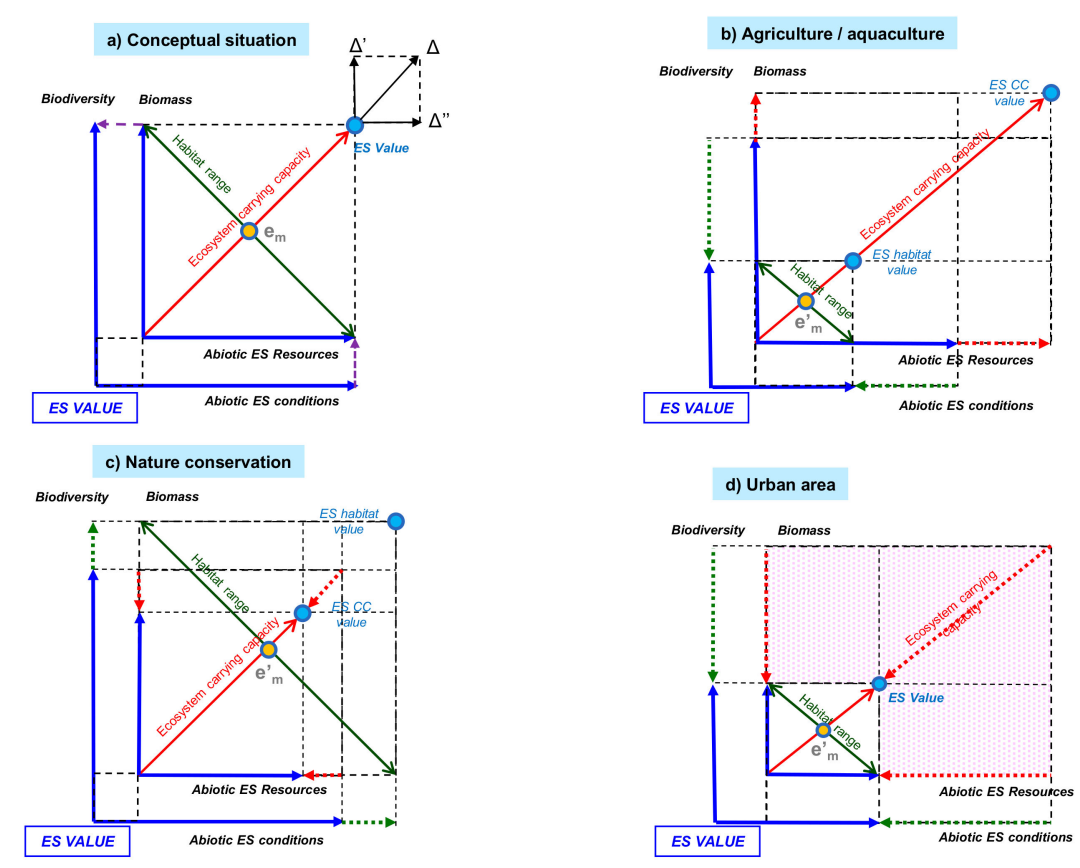

Figure 6. Human interactions. Cases show changes to the conceptual situation (a), cultivations (b), nature management (c), and urban areas (d). Bullets indicate the minimum equilibrium in natural $\left(\mathrm{e}_{\mathrm{m}}\right)$ and managed $\left(\mathrm{e}_{\mathrm{m}}^{\prime}\right)$ ecosystems, and the differentiation between habitat value and ES CC value in managed ecosystems. (Notations: CC, carrying capacity; e and $\mathrm{e}^{\prime}$, ecosystem equilibrium; ES, ecosystem).

Increase of ES CC is described by McNaughton et al. [52] in terms of a species' niche width, with species addition to the community supposing an accompanied increase in carrying capacity (K) and/or niche compression, based on three possibilities (Figure 6a):

(a) species are added to the system in direct proportion to $\mathrm{K}$ increase $(\Delta)$;

(b) species are added more rapidly than $\mathrm{K}$ increases, so niches are squeezed $\left(\Delta^{\prime}\right)$;

(c) species are added less rapidly than $\mathrm{K}$ increases so that niches expand with increasing richness $\left(\Delta^{\prime \prime}\right)$. 
Knowing the relationships between species and niche width is particularly important for water management in the case of invasive species that may have limiting impacts on ecosystem services (see [53]).

The cases in Figure 6 show the differentiation between HR and ES CC, representing different ES values, causing shifts of the optimal natural equilibrium $e_{p}$. Natural undisturbed conditions are expected to meet the conceptual situation (a) with the equilibrium point $\mathrm{e}_{\mathrm{p}}$ that indicates the maximum equilibrium potential, and ES value that includes both $\mathrm{HR}$ value and ES CC value. The ratio is optimal when for a given HR, HR and ES CC are the diagonals of the same rectangle: the potential HR of the habitat is represented by species that fully occupy all available niches within the habitat. All other intersections show impacted situations.

Minimum ES conditions are established by EQSs $\left(\mathrm{e}_{\mathrm{m}}\right)$ that should set save limits to the factors mentioned: the observed equilibrium e, between $\mathrm{e}_{\mathrm{p}}$ and $\mathrm{e}_{\mathrm{m}}$, is expected to reflect good environmental status (SoE) within the range of natural variation. In doing so, EQSs also mark the availability of abiotic and biotic ES G\&Ss. The latter is noticed by Dudgeon [13], concluding that "water scarcity, drainage-basin degradation, and increasing human demands completely override ecosystem requirements for water in parts of China and India."

\section{Using EQSs to Maintain an Ecosystem Equilibrium}

Although Figure 7 is an oversimplification of reality, it illustrates the interdependence between ecosystem equilibrium, ES resilience, and EQSs. An ES equilibrium represents a natural or a human-influenced equilibrium. The natural equilibrium (e) is not a fixed environmental state (SoE), but a combination of ranges and fluctuations of natural variables that reflect the ES resilience. The observed natural equilibrium e is expected to be in between the maximum potential $\left(\mathrm{e}_{\mathrm{p}}\right)$ and the minimum $\left(e_{m}\right)$ equilibrium state. The difference $(\Delta \mathrm{e})$ means that less resources are used, and hence, less biomass (e.g., smaller populations) is produced than its potential under optimal conditions. Hereby, the assumption is that a stable ES show minimum conditions that need to be maintained to guarantee their ES functioning and biodiversity. When e coincides with $\mathrm{e}_{\mathrm{m}}$ on the HR line, a critical level is reached below which a new equilibrium will be obtained (situation $\mathrm{HR}^{\prime}$ ) showing lower biodiversity.

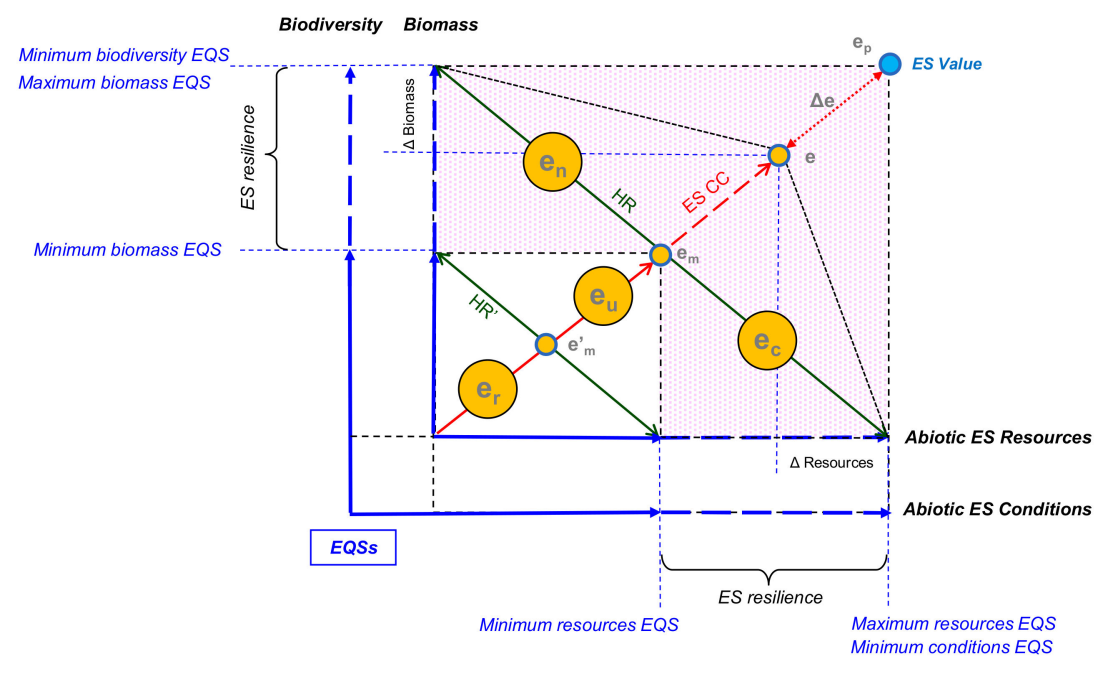

Figure 7. Environmental quality standards (EQSs). Optimal EQSs equal natural conditions of HR and ES CC (e), but most EQSs indicate at present minimum levels ( $\left.\mathrm{e}^{\prime}\right)$ of biota and ES protection. Effective EQSs should cover a harmonized set of values for the key ecosystem factors. The lower the EQSs, the higher the ES G\&Ss potential, which can be enhanced by increase of ES CC. Cases are shown of policies that favour ES value by means of species protection $\left(e_{n}\right)$ or biomass production $\left(e_{c}\right)$, or reduce ES value in the case of urban areas $\left(e_{u}\right)$ and water reservoirs $\left(e_{r}\right)$. 
Minimum values can be established by means of EQSs. EQSs indicate levels of protection and ideally coincide with the boundaries of ES resilience, and as such mark the limits of sustainable use (or harmful impacts) of ES G\&Ss. Hence, depending on the type and use of the habitat, EQSs define minimal standards for protection and ES G\&Ss maximal use. At present, EQSs mainly apply to abiotic ES conditions (habitat protection) and biodiversity (species protection), but not or less to biomass production and resources availability. Recognizing that the natural equilibrium also depends on the two latter main factors requires at least to discuss the potential application of EQSs to these factors. As a result, it can be simply stated that: (1) the natural equilibrium e can be expressed as an ES value; (2) the ES value combines an ES CC value and a HR value; (3) to HR value, minimum EQSs of ES conditions and biodiversity apply; 4) to ES CC, value minimum and maximum EQSs of ES resources and biomass apply.

Sustainable development implies limited use of ES value in order to maintain ecosystems, established by means of EQSs. EQSs are developed to assess the effects of disturbances by human activities, comparing the observed environmental status with an impact threshold. Exceeding EQS values means causing ecosystem damage. If it is agreed that EQSs also indicate the limits of natural variability and dynamism of ecosystems (which is: the degree of fluctuation of ecological parameters), then the conclusion should be that exploitation of natural resources must not exceed the EQS limits. When ES variability also reflects ES resilience, then EQSs relate to both ES stability and the provision of ES G\&Ss, along with their role as environmental damage thresholds (Figure 7). EQSs should, therefore, not only be used for environmental status assessments, but also to indicate the limits of ecosystem variability and dynamism, and by consequence, the exploitation of natural resources.

The rationale of ES value is also applicable to EQSs, distinguishing between biotic EQSs of biodiversity and biomass on the one hand, and abiotic EQSs of habitat conditions and resource availability on the other hand. EQSs are intended to protect the natural environment, with the perspective of maximization of biodiversity and/or habitats, which, in fact, only allows 'default setting' of EQSs equal to the natural (pristine, unimpacted) conditions. Natural conditions are supposed to represent an optimal and balanced status (e, ES equilibrium), with maximal biodiversity and optimal resources and habitat conditions. 'Balanced' means in an intermediate or final stage of natural development, although there might be also a deliberate choice of a human intervention to opt for an intermediate succession level. Policy and management should apply the stand-still principle to this situation: conditions related to any choice of equilibrium point are not expected to deteriorate. However, since humans claim part of the ES value for their own purposes, EQSs are compromises between ES G\&Ss and environmental protection, defined as minimum protection levels. EQSs reflect minimum SoE conditions, lower than optimal, but within the range (or ultimately at the lower limit e') of the ecosystem's resilience. This means that, if the observed environmental status is within this range, habitat conditions in general are secured, but not optimal since populations may decline or vulnerable species may disappear with biomass or biodiversity as low as the minimum $\mathrm{e}_{\mathrm{m}}$. Hence, ES G\&Ss indicate the nature and degree of ES use (available commodities) on the one hand, although limited by EQSs that define the level of abstraction and environmental hazard, and as such the boundaries of sustainability. Griffith [54] offers a cogent illustration of natural forests and wetlands replacement with agricultural and urban land uses, and how this relates to ensuring a biotic index reflecting unimpaired conditions. A variety of EQSs can be defined for each factor considered, and applied to the water domain, this includes, for instance (Figure 7):

- EQS biodiversity: species distribution (occurrence), species richness (e.g., diversity indices, species rareness);

- EQS biomass: limits on population growth of common species, minimal density values of rare or sensitive species, absence of visual indicators (e.g., eutrophication);

- EQSs habitat resources: minimum and maximum values of physico-chemical parameters;

- EQSs habitat conditions: hydro-morphology (e.g., river sinuosity, pool-riffle pattern), presence of host species. 
- In this context, two atypical EQS categories may occur:

- EQSs of non-natural habitats: urban areas, cultivations and reservoirs are also ESs with ES value, but the ES G\&Ss and objectives are different;

- EQSs of non-habitat resources: either non-natural substances or natural toxic substances, for which maximum values are set.

Species protection is a primary, and maintaining biodiversity a non-negotiable condition for policy and management. There can be no deliberate choice to reduce the number of species [45], except on locations this should favour rare species (such as pests and invasive species control). Minimum abiotic ES conditions should meet maximum biodiversity, although minimizing abiotic conditions implies resources reduction and hence, lower biomass. However, lower biomass production will result in unexpected species loss, decreasing population density and/or changes in species evenness. Availability of ES G\&Ss is, therefore, restricted to only parts of ES value (minerals, space, life stock). Additional resources can be obtained by exploring new areas or by ES CC increase (intensification of biomass production by means of cultivations). EQSs determine the restrictions on ES G\&Ss, but are, in practice, compromises between maintaining or restoring natural conditions and degradation by use. Both EQSs and ES G\&Ss should be formulated as policy and management objectives, which make them potentially conflicting in cases ES use exceeds ES CC. The challenge of water management is to maintain the environmental effects of resource abstractions, discharges of pollutants and other impacts within the habitat ranges of natural variables and/or resilience. In this way, sustainable abstraction of ES G\&Ss becomes dependent of the direct use of abstracted resources and harvested biomass. Ge et al. [1] states that ecosystems with a higher diversity are also more resilient, but conflict with modern agriculture and food processing technologies that result in increased vulnerability and decrease of ES G\&Ss by loss of biodiversity and ecosystem functioning.

As a conclusion, it is recommended to establish sets of EQSs, containing both 'impact EQSs' that define limits of disturbances, and 'intrinsic EQSs' that define minimal ecological characteristics:

- for all environmental compartments (aquatic, terrestrial and atmospheric);

- for the primary determining biotic and abiotic factors: biodiversity, biomass, habitat conditions, and abiotic resources;

- in particular for the water compartment: water quality (substances), water quantity (flows, levels, volumes), hydro-morphology, and aquatic biota;

- as minimum (minerals, nutrients, water quantities), optimum, and maximum (dangerous substances, nutrients) values of physical, chemical and biological parameters.

\section{Sustainable Ecological Limits}

Sustainable development requires that the amount of abstracted ES G\&Ss remains within the EQS limits, avoiding environmental harm. Exceeding the EQS limits indicates a significant environmental pressure and significant loss of (or damage to) biodiversity. Biodiversity is metricized as biotic value and according to the definition of carrying capacity, the biotic value depends on the available abiotic resources. The quantity of resources that is used by life forms is called 'abiotic ecosystem resources'. This is only a small part of the natural resources of which large parts remain unused by organisms because of unavailability. However, mining products (fossil fuels, rare earths, minerals) and fossil water may become available by technical means for human profit as abiotic natural resources directly feeding the economy. The remaining part, which is still the vast majority of the earth's underground, will remain un-exploitable and therefore unaccounted. Sustainable economic growth must be effectuated within the limits of available ecosystem value and additional abiotic natural resources. It is important to note that the ecosystem's carrying capacity-the point the biomass of a population stops increasing-differs from the economic carrying capacity, based on exploitation and management strategies [22,45]. Hereby, the adverse effects of polluting substances released into the ecosystem are omitted, although it is obvious that these negative feed-backs further limit resources availability (Figure 8). 


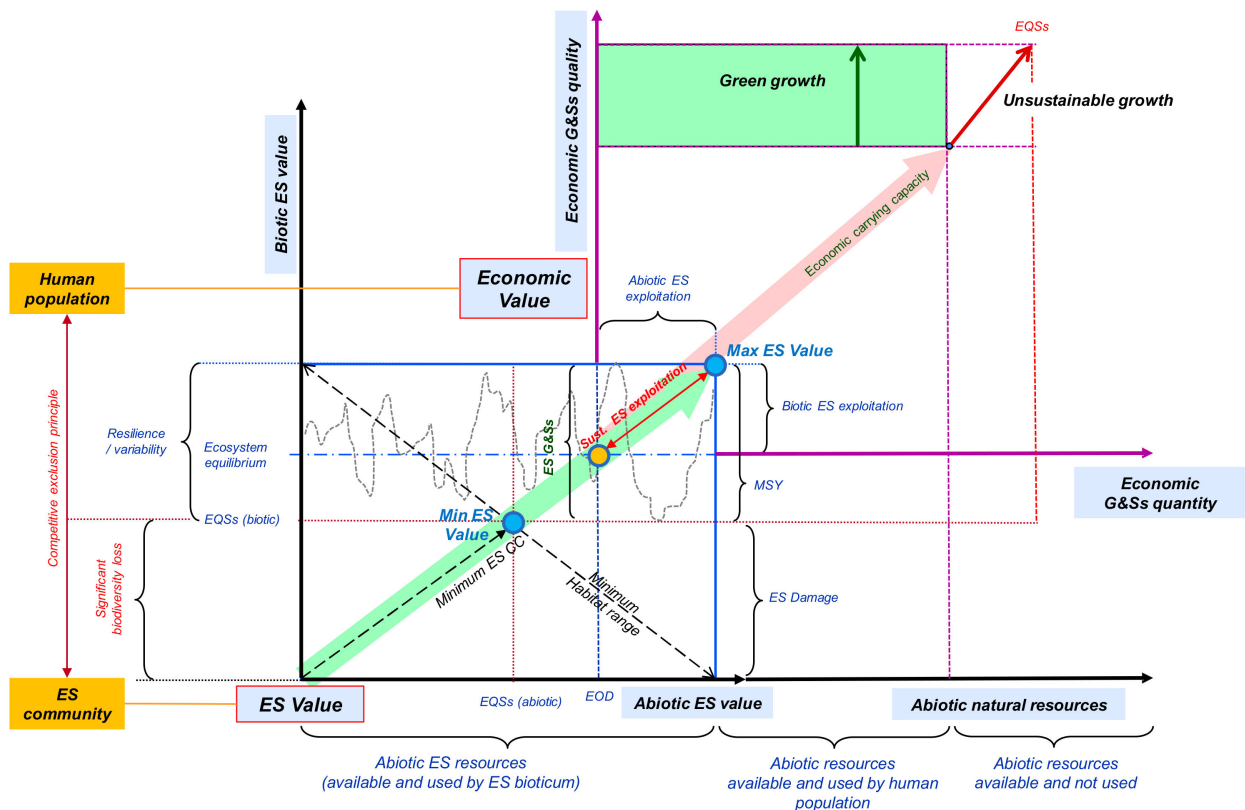

Figure 8. Ecosystem and economic carrying capacity. The exploitation of ecosystems by ecosystem goods and services (ES G\&Ss) depends on the environmental quality standards (EQSs) established, on their turn marking the resilience of ecosystems. Minimum EQSs mark the area of sustainable use and sustainably managed ecosystems. Within this range, the ES CC limits the ES goods that can be used (MSY: maximum sustainable yield). Over-exploitation—of which the Earth Overshoot Day (EOD) is an example-equals to significant ecosystem stress or damage. It is supposed that abiotic and biotic EQSs relate to each other in a simple way. Green growth is achievable within the EQSs and ES G\&Ss limits. Note that the schema indicates the additional use of non-ecosystem resources in the case they have no environmental impacts.

It is clear that the ES value is supported by the ecosystem community and the economic value by the human population. Conflicts arise when the abstraction of ES G\&Ss exceeds the EQS limits, breaking the resilience of the natural community and resulting in significant biodiversity loss. Moreover, it is not required that a large number of EQSs are being exceeded to call an ecosystem significantly impacted since, according to Liebig's Law of the Minimum, the shortage of a single resource parameter-space and water are good examples-is determining. From this, the conclusion can be drawn that sensitivity of ecosystems depends on the overuse by humans of the most limiting factor sustaining ecosystems. In many cases, water is a limiting factor. However, it is not always a common policy objective, nor a managerial practice to limit human activities and natural stock use according to critical limiting factors. Instead, a trial and error approach is still the rule, resulting in hasty measures to cope with emerging environmental problems. With this, the domain of risk analysis, modelling and substance balances is entered. Since the ecological carrying capacity is limiting the biotic value (life forms) according to the available abiotic resources, and since EQSs are defined to protect organisms (including human beings), EQSs should also be established to set margins to abiotic ES resources (abiotic EQSs). Applied to the water system, the minimum levels to be maintained in order to protect aquatic and water-dependent ecosystems are called environmental flows (E-flows, ecosystem flows). Ecosystem water quantity standards related to E-flows hardly exist but gain attention within the EU. However, for reasons of simplicity, it is supposed that abiotic and biotic EQSs mutually correspond to each other. This is not the case in practice because of the complex relationships between the bioticum and abioticum and since biotic EQSs are badly understood and hardly defined at a small scale.

The diverse forms of ES stock use that are called 'ecosystem goods and services' (ES G\&Ss) (Figure 8) compare, in economic terms, to abiotic and biotic natural resources exploitation in the 
physical and non-physical sense. Yield is the exploitation of biotic natural resources. The 'maximum sustainable ecosystem stock use' is the amount of ES G\&Ss retrieved and obtained within the limits of the EQSs. This supports the viewpoint of England [12] that the scale of economic activity is constrained by the remaining stock of natural capital and by its productivity. The biological component is called 'maximum sustainable yield' (MSY). In the context of resource efficiency policy, the following definition of sustainable yield of Walker et al. [55]) (cited in [56]) is more appropriate: "The sustainable yield of natural capital is the ecological yield that can be extracted without reducing the base of the capital itself, i.e., the surplus generated with maintaining nature's services at the same or increasing level over time." In this context, Sampantamit et al. [57] illustrates overexploitation by fisheries in Thailand. In order to perform sustainable economic activities maintaining the ecosystem equilibrium, exploitation of ES G\&Ss must be compensated with ES recovery of which the conditions are different. When economic development becomes limited by EQSs, green growth reflects the production area in which no or minimal additional resources are used to produce one additional unit. This is the case with aquaponics.

Recognizing the same concepts-such as carrying capacity, resilience and vulnerability- apply to both ecological and socio-economic systems, and considering the dependency of the human system on ecosystems, production systems need to incorporate processes of both systems to guarantee sustainability. As such, Ge et al. [1] addresses the lack of resilience thinking in biological production systems in which productivity and resource use efficiency prevail. It is, therefore, essential to develop appropriate tools.

\section{Results and Applications of the Conceptual Model}

Thus far, the proposed concept includes the following products:

- a selection of ES key factors;

- the enlargement of the socio-economic valuation scheme with a natural value classification, related to ES G\&Ss;

- the enlargement of the EQSs framework with intrinsic natural EQSs;

- a description of ES limits and the 'Ecosystem-economy' nexus.

The importance of a conceptual model is that it allows to structure different approaches and tools from a single point of view. The proposed ES key factors are important in providing opportunities to simplify ES complexity and to connect to water management by means of technical tools such as biotic indices and aquatic modelling.

ES key factors help to explain biotic indices (or scores) as an indicator of water quality. Biological water quality indices normally derive their indicator value from the combination of the number of taxa encountered in a sample and the sensitivity to pollution of a selected number of taxa. The number of taxa stands for biodiversity; the taxonomic sensitivity reflects different modes of respiration (which is a functional trait) and hence, the oxygen concentration in the water body (which is one parameter of the natural condition). As such, the biotic index is representative of the habitat range of a water body and its limited conditions. Indeed, oxygen depletion is the most limiting factor in water bodies with organic pollution, lowering biodiversity by reducing niche width for those species requiring high(er) oxygen levels. However, ecosystem functioning and communities are influences by multiples stressors, causing hydrological, chemical, and physical variability [58]. Additionally, since biotic indicators only reflect $\mathrm{HR}$, it is challenging to develop an advanced indicator integrating both HR and ES CC.

Environmental indicators are an important evaluation tool in the way they allow to combine physical environmental changes (e.g., trends of improving water quality) with governance. The selected ES key and additional factors are or can be used as environmental indicators, providing, at the same time, information on the state or trend of a variable and on the policy and management achievements. Ten out of 22 sustainability indicators for lakes and reservoirs formulated by Ho et al. [59] deal with ES key factors (abiotic conditions: 4, abiotic resources: 2, biomass: 1, biodiversity: 2), four with additional 
factors (HR: 3, ES CC: 1), but 11 with policy and management. There is a potential for ES factors to balance the environmental/governance indicator set.

The nexus 'ES key factors-EQSs-ES G\&Ss' may help to simplify the complex species traits and balance models that support environmental management. Key factor based EQSs are essential to develop water mass and load balances. Substance balances link ecosystem with economic modelling and decision-making. Developing physical account balances, including substance flows and load balances (for an example, see [28]), should precede the monetary valuation. This is the basic approach of the UN SEAAW concept [30]. Water balances are essential to estimate social and economic costs and benefits of limited resources and commodities, or ecosystem restoration. As such, substance balances reflecting a societal equilibrium (e.g., a fair and sustainable allocation of water resources to users) should facilitate market environmentalism, which is the kind of governance that conciliates economic growth, allocation efficiency, and environmental conservation [60]. Using the nexus 'ES key factors-EQSs-ES G\&Ss' is expected to gain importance with complex modelling based on Bayesian Networks and/or 'nexus thinking' related to (combinations of) environmental factors-such as the 'water-energy-food' nexus-and decision-making. In this respect, Torres et al. [61] stresses the importance of conceptualization of nexus modelling and the inclusion of the ecosystem and related ecosystem services as a central element, as well as the need to restrict the number of elements included in the model structure. Bayesian Networks are decision support tools that are widely used for analyzing impacts on aquatic systems and scenario-analyses in water resources management, although this requires the identification of key system variables and understanding of their mutual relationships [62]. An example of groundwater overexploitation for crop production and the economic consequences thereof is provided by Mirzaei et al. [63].

\section{Discussion}

The selected key factors seem of critical importance to understand properties of ES functioning such as carrying capacity, habitat range, and ecosystem resilience. Abiotic resources, biomass and carrying capacity are quantitative aspects of ecosystems; abiotic conditions, biodiversity and habitat range are qualitative ecosystem properties. A limited number of factors helps to explain issues in a simple and clear way. These factors are key indicators of ES functioning, and also allow to show changes in process interactions. They all contribute to ES resilience and can be expressed as EQSs by means of ecosystem requirements or values derived from modelling tools. These tools are diverse and include, apart from the already mentioned functional trait analyses and substance flow balances, also population dynamics, physical accounts, valuation techniques, and impact assessments. Therefore, the emphasis is on the extension of the existing 'impact EQSs', setting maximum impact standards, with 'intrinsic EQSs' that allow to define a minimum level of environmental quality. Other than 'impact EQSs' that aim to regulate disturbances, intrinsic EQSs reflect the natural conditions to be maintained or restored. The combined set of EQSs allows to define sustainable measures, in the sense of limiting the use of natural resources and meeting the required ecosystem quality. Measures include species and habitat protection, nature restoration, or limitations on the use of ES G\&Ss, that are expressed in terms of parameter values, the presence of target species, the occurrence of habitat types, etc. Economic tools allow to quantify the effects of measures on the availability of resources and to express the socio-economic impact in monetary terms.

The economic dependence on natural capital with the objective of sustainability has been studied by a number of environmental economists. Faucheux et al. [64] and Gómez-Baggethun et al. [46] investigated weak and strong sustainability in terms of valuation and monetization. Faucheux et al. [64] considers these two forms complementary economic concepts: weak sustainability is a subtraction from Gross National Product by including ecological assets and services, and strong sustainability is the maintenance of natural capital stocks or environmental functions. In this respect, strong sustainability aims for maintaining stocks of 'critical natural capital' according to minimum levels of protection, and the sustainment of economic capital in a functional symbiosis with the natural capital. This cogently 
fits the exposed societal values concept. The intrinsic EQSs reduce and integrate the complexity of natural processes to a set of physical values as a basis for environmental and economic modelling and accounting.

Impact and intrinsic EQSs fundamentally differ in the way they should be established and applied. Impact EQSs are, in general, fixed minimum or maximum values in order to reach or maintain a minimum environmental quality (basic EQSs), eventually with further diversification based on, e.g., an aquatic typology (as in the case of the EU Water Framework Directive), but applicable to a large set of cases. Intrinsic EQSs are case-specific and targeted to particular habitat conditions and potentials, and are, therefore, more challenging as setting dynamic values requires more competences, labour and tools. Impact EQSs can be legally enforced, whilst intrinsic EQSs require implementation by means of management plans.

Some opinions formulated by different authors (e.g., [12,38]) on the natural and economic capital dependencies, force to make some statements with respect to the topics discussed: (1) the economy and many economists still believe and behave as if natural resources are infinitely available and nature is a bottomless sink for wastes, (2) the economy is not including environmental externalities: intrinsic natural value, pollution, or the true costs related to ES G\&Ss, (3) there are 'limits to growth' as postulated by Meadows and collaborators in 1972 and Daly and Costanza in the 1990s, and (4) societal functioning depends on economic valuations that do not reflect the natural capital value. The idea of a critical minimum level of natural capital, below which ecosystem services become insufficient to secure human survival gains support from economists, warns that shifting towards a steady-state economy will become inevitable [12]. Costanza et al. [10] notes that "Issues of sustainability are ultimately issues about limits," not only on resources, but also with respect to fairness, equity and distribution across generations. A shortcoming of EQSs is that they are used as or expected to represent a static level of ES resilience within a barycentric concept of a societal equilibrium, showing a single, deterministic, predictable and mechanistic state. A societal equilibrium should not be identified as a unique equilibrium point, but as an area of change within the boundaries of the metrics that characterize the conditions of each societal capital. This matches the concept of social-ecological resilience [36]. In reality, social, economic and natural systems are dynamic and develop within boundaries. Critical developments such as climate change, resources depletion, and biodiversity loss, shift to the lower margins of these boundaries and challenge systems thinking. With the focus on understanding complexity, dynamics, risks and uncertainties of systems and processes, systems thinking aims to pay more attention to instability, adaptiveness, innovation and change management, rather than to control, stability and consistency [26].

It is only a small step from water management to overall governance. In this respect, it is worthwhile to consider how this approach can contribute to the UN Sustainable Development Goals (SDGs, [65]). Conceptually based on aquatic ecosystems, the items discussed relate to 9 out of the 17 SDGs and directly affect 29 out of 168 targets defined as specifications of the goals. In this respect, they deal with food production, sustainable resource use and production and consumption, biodiversity and habitat protection, water use, water quality improvement, integrated policy and management of water resources, and development of resilient urban areas. The target to be mentioned in particular: " 15.9 By 2020, integrate ecosystem and biodiversity values into national and local planning, development processes, poverty reduction strategies and accounts."

\section{Conclusions}

The main focus of this paper deals with the selection of key factors that characterize ecosystems in terms of natural resources valuation and the description of their properties in ecosystem processes. Natural values are either extrinsic or intrinsic and can be expressed as nodes in a network of physical entities and processes. The proposed values scheme relates ES G\&Ss with socio-economic and natural values. It seems possible to include the total natural value in decision-making, quantifiable in a way it indicates the limits of ES G\&Ss. Key nodes are selected as key factors of ES functioning: abiotic 
conditions and resources, biomass, and biodiversity. They are mutually interacting and are at the basis of the additional factors habitat range and ecosystem carrying capacity. In a diagram, the intersection of the additional factors indicates a minimum ecosystem equilibrium. Key and additional factors can be expressed as EQSs for policy and management. This means that intrinsic natural values can be expressed as intrinsic EQSs, additional to the existing impact EQSs.

The main findings read as follows:

- Valuing and valuation apply to values of economy and nature and can be integrated in a common scheme, adding a typology of natural valuation to the combination of economic valuation and ES G\&Ss.

- Since the economy and nature are both complex systems, it is essential to identify key ecosystem factors for valuing and valuation: abiotic conditions and resources, biomass, biodiversity. They are at the basis of ecosystem properties, including habitat range and carrying capacity, and ultimately also resilience.

- Expression of these factors as a combined set of impact and intrinsic EQSs is essential to support decision-making aiming for sustainability.

- EQSs reduce the ecological complexity into figures and requirements that allow to define legal provisions and physical and economic accounting.

- Complexity requires an integrated ecological-economic modelling approach, the ecological models including functional traits analyses and substance balances.

Author Contributions: Conceptualization, R.V., with support of P.L.M.G.; methodology, R.V.; writing—original draft preparation, R.V.; writing-review and editing, P.L.M.G.; supervision, P.L.M.G. All authors have read and agreed to the published version of the manuscript.

Funding: This research received no external funding.

Acknowledgments: The authors are very grateful to the two anonymous reviewers of this paper and to academic editor, Daniela Malcangio, for their valuable comments.

Conflicts of Interest: The authors declare no conflicts of interest.

\section{Acronyms and Abbreviations}

$\begin{array}{ll}\text { e } & \begin{array}{l}\text { equilibrium } \\ \text { environmental information cycle }\end{array} \\ \text { EOD } & \text { Earth Overshoot Day } \\ \text { EQS } & \text { environmental quality standards } \\ \text { ES } & \text { ecosystem } \\ \text { (ES) CC } & \text { (ecosystem) carrying capacity } \\ \text { ES G\&S } & \text { ecosystem goods and services } \\ \text { EU } & \text { European Union } \\ \text { GASI } & \text { governance by actor-subject impact analysis } \\ \text { HR } & \text { habitat range } \\ \text { MSY } & \text { maximum sustainable yield } \\ \text { P\&M } & \text { policy and management } \\ \text { PTM } & \text { Pentatope Model } \\ \text { SDG } & \text { sustainable development goal } \\ \text { S-E } & \text { socio-economic } \\ \text { SoE } & \text { state of the environment } \\ \text { TEN } & \text { Total Economic Value } \\ \text { TNV } & \text { Total Natural Value } \\ \text { V\&V } & \text { valuing and valuation }\end{array}$




\section{References}

1. Ge, L.; Anten, N.P.R.; van Dixhoorn, I.D.E.; Feindt, P.H.; Kramer, K.; Leemans, R.; Meuwissen, M.P.M.; Spoolder, H.; Sukkel, W. Why we need resilience thinking to meet societal challenges in bio-based production systems. Curr. Opin. Environ. Sustain. 2016, 23, 17-27. [CrossRef]

2. Ceola, S.; Montanari, A.; Krueger, T.; Dyer, F.; Kreibich, H.; Westerberg, I.; Carr, G.; Cudennec, C.; Elshorbagy, A.; Savenije, H.; et al. Adaptation of water resources systems to changing society and environment: A statement by the International Association of Hydrological Sciences. Hydrol. Sci. J. 2016, 61, 2803-2817. [CrossRef]

3. Gupta, J.; Pouw, N. Towards a trans-disciplinary conceptualization of inclusive development. Curr. Opin. Environ. Sustain. 2017, 1-8. [CrossRef]

4. EEA. Circular by Design—Products in the Circular Economy; EEA Report No 6/2017; European Environment Agency: Copenhagen, Denmark, 2017. [CrossRef]

5. UN EMG. Working towards a Balanced and Inclusive Green Economy: A United Nations System-wide Perspective; Prepared by the Environment Management Group; United Nations: Geneva, Switzerland, 2011.

6. UNEP. Measuring Water Use in a Green Economy; A Report of the Working Group on Water Efficiency to the International Resource Panel; United Nations Environment Programme: Nairobi, Kenya, 2012.

7. Brundtland, G.H. Report of the World Commission on Environment and Development: Our Common Future. Available online: http://www.un-documents.net/wced-ocf.htm (accessed on 4 July 2018).

8. Costanza, R.; d’Arge, R.; de Groot, R.; Farber, S.; Grasso, M.; Hannon, B.; Limburg, K.; Naeem, S.; O’Neill, R.V.; Paruelo, J.; et al. The value of the world's ecosystem services and natural capital. Nature 1997, 387, $253-260$. [CrossRef]

9. Bateman, I.J.; Mace, G.M.; Fezzi, C.; Atkinson, G.; Turner, K. Economic Analysis for Ecosystem Service Assessments. Env. Resour. Econ. 2011, 48, 177-218. [CrossRef]

10. Costanza, R.; Cleveland, C.J.; Perrings, C. The Development of an Ecological Economics; Edward Elgar Press: Cheltenham, UK, 1997; pp. 45-67.

11. Costanza, R.; Andrade, F.; Antunes, P.; van den Belt, M.; Boesch, D.; Boersma, D.; Catarino, F.; Hanna, S.; Limburg, K.; Low, B.; et al. Ecological economics and sustainable governance of the Oceans. Ecol. Econ. 1999, 31, 171-187. [CrossRef]

12. England, R.W. Natural capital and the theory of economic growth. Ecol. Econ. 2000, 34, 425-431. [CrossRef]

13. Dudgeon, D. The most endangered ecosystems in the world? Conservation of riverine biodiversity in Asia. Verh. Internat. Verein. Limnol. 2002, 28, 59-68. [CrossRef]

14. Kingsford, R.T. Ecological impacts of dams, water diversions and river management on floodplain wetlands in Australia. Aust. Ecol. 2000, 25, 109-127. [CrossRef]

15. European Commission. Mapping and Assessment of Ecosystems and Their Services an Analytical Framework for Ecosystem Assessments under Action 5 of the EU Biodiversity Strategy to 2020; European Commission: Brussels, Belgium, 2014. [CrossRef]

16. Braat, L. The predictive meaning of sustainability indicators. In Search of Indicators of Sustainable Development. Environment \& Management; Kuik, O., Verbruggen, H., Eds.; Kluwer Academic Publishers: Dordrecht, The Netherlands, 1991; pp. 57-70. [CrossRef]

17. Folke, C. Resilience: The emergence of a perspective for social-ecological systems analyses. Glob. Environ. Chang. 2006, 16, 253-267. [CrossRef]

18. Pinto, R.; de Jonge, V.N.; Neto, J.M.; Domingos, T.; Marques, J.C.; Patrício, J. Towards a DPSIR driven integration of ecological value, water uses and ecosystem services for estuarine systems. Ocean Coast. Manag. 2013, 72, 64-79. [CrossRef]

19. European Environment Agency. European Environment-State and Outlook 2015: Assessment of Global Megatrends; European Environment Agency: Copenhagen, Denmark, 2015. [CrossRef]

20. OECD. OECD Environmental Outlook to 2050; OECD Publishing: Paris, France, 2012. [CrossRef]

21. European Commission. General Union Environment Action Programme to 2020. Living Well, within the Limits of Our Planet; European Commission: Brussels, Belgium, 2014. [CrossRef]

22. De Jonge, V.N.; Pinto, R.; Turner, R.K. Integrating ecological, economic and social aspects to generate useful management information under the EU Directives 'ecosystem approach'. Ocean Coast. Manag. 2012, 68, 169-188. [CrossRef] 
23. Hoekstra, A.J.; Chapagain, A.K.; Aldaya, M.M.; Mekonnen, M.M. Water Footprint Assessment Manual. Setting the Global Standard. Water Footprint Network; Earthscan Ltd.: London, UK, 2011.

24. European Environment Agency (EEA). Results and Lessons from Implementing the Water Assets Accounts in the EEA Area-From Concept to Production; European Environment Agency: Copenhagen, Denmark, 2013.

25. Martínez-Alier, J. The Environmentalism of the Poor-A Study of ecological Conflicts and Valuation; Edward Elgar: Cheltenham, UK, 2002.

26. Morgan, P. The Idea and Practice of Systems Thinking and Their Relevance for Capacity Development. Available online: https://ecdpm.org/wp-content/uploads/2005-Idea-Practice-Systems-Thinking-RelevanceCapacity-Development.pdf (accessed on 8 November 2019).

27. Vannevel, R. The Pentatope Model: A holistic approach for analysing and reviewing environmental complexity. Sustain. Water Qual. Ecol. 2013, 1-2, 10-23. [CrossRef]

28. Vannevel, R. Using DPSIR and Balances to Support Water Governance. Water 2018, 10, 118. [CrossRef]

29. UN. Water, a Shared Responsibility; UNESCO/Division of Water Sciences: Paris, France, 2006.

30. UNSD. SEEA-Water-System of Environmental-Economic Accounting for Water. Available online: http: //unstats.un.org/unsd/envaccounting/seeaw/seeawaterwebversion.pdf (accessed on 8 November 2019).

31. Keeler, B.L.; Polasky, S.; Brauman, K.A.; Johnson, K.A.; Finlay, J.C.; O’Neille, A.; Kovacs, K.; Dalzell, B. Linking water quality and well-being for improved assessment and valuation of ecosystem services. Proc. Natl. Acad. Sci. USA 2012, 109, 18619-18624. [CrossRef]

32. Millennium Ecosystem Assessment. Ecosystems and Human Well-being: A Framework for Assessment; Island Press: Washington, DC, USA, 2003.

33. Apitz, S.E. Ecosystem Services and Environmental Decision Making: Seeking Order in Complexity. Integr. Environ. Assess. Manag. 2012, 9, 214-230. [CrossRef]

34. Berkes, F. Environmental Governance for the Anthropocene? Social-Ecological Systems, Resilience, and Collaborative Learning. Sustainability 2017, 9, 1232. [CrossRef]

35. Poff, N.L. Landscape filters and species traits: Towards mechanistic understanding and prediction in stream ecology. J. N. Am. Benthol. Soc. 1997, 16, 391-409. [CrossRef]

36. Menezes, S.; Baird, D.J.; Soares, A.M.V.M. Beyond taxonomy: A review of macroinvertebrate trait-based community descriptors as tools for freshwater biomonitoring. J. Appl. Ecol. 2010, 47, 711-719. [CrossRef]

37. Forio, M.A.E.; Goethals, P.L.M.; Lock, K.; Asio, V.; Bande, M.; Thas, O. Model-based analysis of the relationship between macroinvertebrate traits and environmental river conditions. Environ. Model. Softw. 2018, 106, 57-67. [CrossRef]

38. OECD. Environmental Outlook and Strategy_Biodiversity; Working Party on Economic and Environmental Policy Integration-Working Party on Economic Aspects of Biodiversity. ENV/EPOC/GEEI/BIO(2001)2/ FINAL; OECD Publishing: Paris, France, 2001.

39. Bremner, J.; Rogers, S.I.; Frid, C.L.J. Methods for describing ecological functioning of marine benthic assemblages using biological traits analysis (BTA). Ecol. Indic. 2006, 6, 609-622. [CrossRef]

40. Ricklefs, R.E. The Economy of Nature. A Textbook in Basic Ecology, 4th ed.; W.H. Freeman and Company: New York, NJ, USA, 1997.

41. Segadelli, S.; Grazzini, F.; Adorni, M.; De Nardo, M.T.; Fornasiero, A.; Chelli, A.; Cantonati, M. Predicting Extreme-Precipitation Effects on the Geomorphology of Small Mountain Catchments: Towards an Improved Understanding of the Consequences for Freshwater Biodiversity and Ecosystems. Water 2020, 12, 79. [CrossRef]

42. CBD. Convention on Biological Diversity. Available online: https://www.cbd.int/convention/text/ (accessed on 12 June 2018).

43. Carmona, C.P.; de Bello, F.; Mason, N.W.H.; Lepš, J. Traits Without Borders: Integrating Functional Diversity Across Scales. Trends Ecol. Evol. 2016, 31, 382-394. [CrossRef] [PubMed]

44. EEA. Perspectives on Transitions to Sustainability; EEA Report-No 25/2017; EEA: Copenhagen, Denmark, 2017. [CrossRef]

45. Stiling, P. Ecology. Theories and Applications, 2nd ed.; Prentice Hall: Upper Saddle River, NJ, USA, 1996.

46. Graham, N.A.J.; Wilson, S.K.; Carr, P.; Hoey, A.S.; Jennings, S.; MacNeil, M.A. Seabirds enhance coral reef productivity and functioning in the absence of invasive rats. Nature 2018, 559, 250-253. [CrossRef] 
47. Gómez-Baggethun, E.; de Groot, R.; Lomas, P.L.; Montes, C. The history of ecosystem services in economic theory and practice: From early notions to markets and payment schemes. Ecol. Econ. 2010, 69, 1209-1218. [CrossRef]

48. Martínez-Alier, J.; Munda, G; O’Neill, J. Weak comparability of values as a foundation for ecological economics. Ecol. Econ. 1998, 26, 277-286.

49. Lautenbach, S.; Mupepele, A.-C.; Dormann, C.F.; Lee, H.; Schmidt, S.; Scholte, S.S.K.; Seppelt, R.; van Teeffelen, A.J.A.; Verhagen, W.; Volk, M. Blind spots in ecosystem services research and challenges for implementation. Reg. Environ. Chang. 2019. [CrossRef]

50. Vitousek, P.M.; Naylor, R.; Crews, T.; David, M.B.; Drinkwater, L.E.; Holland, E.; Johnes, P.J.; Katzenberger, J.; Martinelli, L.A.; Matson, P.A.; et al. Nutrient Imbalances in Agricultural Development. Science 2009, 324, 1519-1520. [CrossRef]

51. Martín-López, B.; Gómez-Baggethun, E.; García-Llorentea, M.; Montes, C. Trade-offs across value-domains in ecosystem services assessment. Ecol. Indic. 2014, 37, 220-228. [CrossRef]

52. McNaughton, S.J.; Wolf, L.L. Dominance and the Niche in Ecological Systems. Science 1970, 167, $131-139$. [CrossRef]

53. Sheehan, R.; Etoundi, E.; Minchin, D.; Van Doninck, K.; Lucy, F. Identification of the Invasive Form of Corbicula Clams in Ireland. Water 2019, 11, 1652. [CrossRef]

54. Griffith, R.W. Estimating the agricultural carrying capacity of catchments based on water quality. Verh.Internat. Verein. Limnol. 2002, 28, 1116-1120. [CrossRef]

55. Walker, B.; Salt, D. Resilience Thinking: Sustaining Ecosystems and People in a Changing World; Island Press: Washington, DC, USA, 2006.

56. Gjoksi, N.; Sedlacko, M. Resource Policies in the Context of Sustainable Development: Current Trends and Challenges Ahead; European Sustainable Development Network: Vienna, Austria, 2011.

57. Sampantamit, T.; Noranarttragoon, P.; Lachat, C.; Goethals, P. Evolution of Fish and Shellfish Supplies Originating from Wild Fisheries in Thailand Between 1995 and 2015. Sustainability 2019, 11, 7198. [CrossRef]

58. Laini, A.; Viaroli, P.; Bolpagni, R.; Cancellario, T.; Racchetti, E.; Guareschi, S. Taxonomic and Functional Responses of Benthic Macroinvertebrate Communities to Hydrological and Water Quality Variations in a Heavily Regulated River. Water 2019, 11, 1478. [CrossRef]

59. Ho, L.T.; Goethals, P.L.M. Opportunities and Challenges for the Sustainability of Lakes and Reservoirs in Relation to the Sustainable Development Goals (SDGs). Water 2019, 11, 1462. [CrossRef]

60. Gómez-Baggethun, E.; Ruiz-Pérez, M. Economic valuation and the commodification of ecosystem services. Prog. Phys. Geogr. 2011, 35, 613-628. [CrossRef]

61. Torres, C.J.F.; Peixoto de Lima, C.H.; de Almeida Goodwin, B.S.; de Aguiar, T.R., Jr.; Fontes, A.S.; Ribeiro, D.V.; da Silva, R.S.X.; Pinto Medeiros, Y.D. Literature Review to Propose a Systematic Procedure to Develop "Nexus Thinking" Considering the Water-Energy-Food Nexus. Sustainability 2019, 11, 7205. [CrossRef]

62. Phan, T.C.; Smart, J.C.R.; Stewart-Koster, B.; Sahin, O.; Hadwen, W.L.; Dinh, L.T.; Tahmasbian, I.; Capon, S.J. Applications of Bayesian Networks as Decision Support Tools for Water Resource Management under Climate Change and Socio-Economic Stressors: A Critical Appraisal. Water 2019, 11, 2642. [CrossRef]

63. Mirzaei, A.; Saghafian, B.; Mirchi, A.; Madani, K. The Groundwater-Energy-Food Nexus in Iran's Agricultural Sector: Implications for Water Security. Water 2019, 11, 1835. [CrossRef]

64. Faucheux, S.; O'Connor, M. Natural Capital, the Greened National Product and the Monetisation Frontier-Establishing a Working Partnership between "Weak" and "Strong" Considerations for Sustainability; Université de Versailles St-Quentin-en-Yvelines: Guyancourt, France, 2000.

65. UN. United Nations Sustainable Development Goals. Available online: https://www.un.org/ sustainabledevelopment/sustainable-development-goals/ (accessed on 8 November 2019).

(C) 2020 by the authors. Licensee MDPI, Basel, Switzerland. This article is an open access article distributed under the terms and conditions of the Creative Commons Attribution (CC BY) license (http://creativecommons.org/licenses/by/4.0/). 